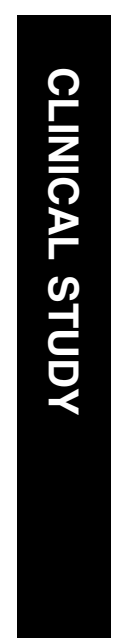

\section{Efficacy and safety of the latanoprost/ timolol maleate fixed combination vs concomitant brimonidine and latanoprost therapy}

${ }^{1}$ Pharmaceutical Research Network LLC, Charleston and SC, USA

\section{${ }^{2}$ Department of} Ophthalmology at the University of South Carolina Columbia, SC, USA

${ }^{3}$ Atlanta Research Company LLC Atlanta, GA, USA

${ }^{4}$ Omni Eye Services Atlanta, GA, USA

${ }^{5}$ Glaucoma Consultants \& Center for Eye Research Mount Pleasant SC, USA

Correspondence: WC Stewart, MD Pharmaceutical Research Network LLC 1639 Tatum Street Charleston SC 29412, USA

Tel.: 843-762-6500

Fax: 843-762-7444

E-mail:prnc@

bellsouth.net

Received: 14 April 2003 Accepted: 6 November 2003

Published online: 19 March 2004

This study was sponsored by Pfizer. The authors have no proprietary interest in any of the product or companies listed.

\section{Abstract}

Aims To evaluate the efficacy and safety of latanoprost/timolol maleate fixed combination (LTFC) given once daily $v$ s the concomitant therapy of brimonidine twice daily and latanoprost once daily in primary open-angle glaucoma or ocular hypertensive subjects. Methods A prospective, double-masked, active-controlled comparison in which qualified subjects had all glaucoma medicines discontinued for 1 month and then were randomized to either LTFC or brimonidine and latanoprost concomitant therapy for 6 weeks. They were then switched to the other treatment regimen. The intraocular pressure (IOP) was measured at 0800,1200 , and $1600 \mathrm{~h}$ at baseline and at the end of Periods 1 and Period 2.

Results In 32 subjects, the diurnal curve of the untreated IOP of $26.0 \pm 3.4$ decreased to $17.8 \pm 2.5$ on LTFC and $17.2 \pm 2.8 \mathrm{mmHg}$ on brimonidine and latanoprost $(P=0.31)$. At 0800 and $1600 \mathrm{~h}$, the IOPs were statistically similar between the groups $(P>0.05)$. At $1200 \mathrm{~h}$ the latanoprost and brimonidine treatment IOP was statistically lower $(16.2 \pm 3.2)$ than LTFC $(18.0 \pm 2.8 \mathrm{mmHg})$. However, the reduced IOP from untreated baseline was not statistically different at each time point and for the diurnal curve for each therapy $(P<0.05)$. Safety was similar between groups for both solicited and unsolicited side effects $(P>0.05)$.

Conclusion This study suggests that LTFC and concomitant therapy of brimonidine and latanoprost provide statistically similar diurnal IOP reduction from an untreated baseline.
WC Stewart ${ }^{1,2}$, JA Stewart ${ }^{1,3}$, DG Day ${ }^{3,4}$,

ED Sharpe ${ }^{5}$ and JN Jenkins ${ }^{1}$
Eye (2004) 18, 990-995. doi:10.1038/sj.eye.6701375 Published online 19 March 2004

Keywords: Latanoprost/timolol; brimonidine; latanoprost

Introduction

Adjunctive (two-medicine) therapy is important to many subjects with ocular hypertension or primary open-angle glaucoma in order to control the intraocular pressure to a level that will help maintain vision long term.

Accordingly, a number of manufacturers have recently produced fixed-combination products to help provide convenience and perhaps greater compliance when treating subjects with glaucoma. One of these, the latanoprost $0.005 \%$ / timolol maleate $0.5 \%$ fixed combination (Xalacom ${ }^{\circledR}$, Pfizer, New York, NY, USA), has recently become available worldwide, except in the United States. Brimonidine $0.2 \%$

(Alphagan $^{\circledR}$, Allergan, Irvine, CA, USA) is also an important medicine for reducing the intraocular pressure that is often used adjunctively and is not yet available in a fixedcombination product.

Recently, Stewart et al ${ }^{1}$ have shown that, over the 12-h daytime diurnal curve, the latanoprost $0.005 \%$ / timolol maleate $0.5 \%$ fixed combination dosed each evening statistically reduced the intraocular pressure more than concomitant brimonidine $0.2 \%$ and timolol maleate $0.5 \%$ each given twice daily between 6 and $12 \mathrm{~h}$ post dosing. ${ }^{1}$

However, in the past few years, brimonidine $0.2 \%$ and latanoprost $0.005 \%$ also have been used together as concomitant therapy. 
Unfortunately, little information is yet available that compares the latanoprost $0.005 \%$ /timolol maleate $0.5 \%$ fixed combination and the concomitant therapy of brimonidine $0.2 \%$ and latanoprost $0.005 \%$.

The purpose of this current trial was to compare the efficacy and safety of the latanoprost $0.005 \%$ / timolol maleate $0.5 \%$ fixed-combination treatment dosed each morning $v$ s brimonidine $0.2 \%$ given twice daily and latanoprost $0.005 \%$ (Xalatan ${ }^{\circledR}$, Pfizer, New York, NY, USA) given each evening in primary open-angle glaucoma or ocular hypertensive subjects.

\section{Materials and methods}

\section{Subjects}

In this study, we included subjects with the following conditions: 18 years or older, willingness to comply with the investigator's and protocol's instructions and sign the informed consent form. The subjects had to demonstrate a clinical diagnosis of primary open-angle, pigment dispersion or exfoliation glaucoma, or ocular hypertension in at least one eye (the study eye). The subjects were also required to have an untreated baseline intraocular pressure between $24-35 \mathrm{mmHg}$ inclusive in the study eye at 0800 at Visit 2 (the non-study eye intraocular pressure had to be treated with either no pharmacologic therapy or the study medication). The subject needed to have a visual acuity of $20 / 200$ or better in both eyes.

We excluded subjects with the following: any abnormality preventing reliable applanation tonometry in the study eye(s), any opacity or subject uncooperativeness that restricted adequate examination of the ocular fundus or anterior chamber in the study eye, any concurrent infectious/noninfectious conjunctivitis, keratitis or uveitis in either eye, any history of allergic hypersensitivity or poor tolerance to any components of the preparations used in this trial, any female who was pregnant or lactating and those of childbearing potential not using reliable means of birth control, any clinically significant, serious, or severe medical or psychiatric condition, any intraocular conventional surgery or laser surgery within the previous 2 months in the study eye(s), unacceptable risk of visual field or visual acuity worsening as a possible consequence of participation in the trial, current therapy with MAO inhibitors or tricyclic antidepressants, progressive retinal or optic nerve disease apart from glaucoma, history of bronchial asthma, severe chronic obstructive pulmonary disease, sinus bradycardia, second- or third-degree atrioventricular block, overt cardiac failure, cardiogenic shock, any anticipated change in systemic hypotensive therapy during the active treatment portion of the trial, unwillingness to accept a risk of iris color or eyelash changes, and inability to understand the trial procedures, and give informed consent. Subjects could not have participated (or had current participation) in any investigational drug or device trial within the 30 days prior to the baseline visit of the trial.

\section{Procedures}

All subjects signed an Institutional Review Boardapproved informed consent document before any procedures were performed. At least 28 days prior to baseline, subjects had a screening exam (Visit 1) performed that consisted of an ocular and systemic history, gonioscopy, visual field (Humphrey Field Analyzer, Program 24-2, San Leandro, CA, USA), and dilated ophthalmoscopy. They also underwent, as well as at other visits in this trial, slit-lamp biomicroscopy, Early Treatment Diabetic Retinopathy Study (ETDRS) visual acuity, and Goldmann applanation tonometry. If subjects met the inclusion and exclusion criteria, they had their current glaucoma medication discontinued. Subjects were then asked to return in 4 weeks for the baseline visit.

At Visit 2 (Day 0, baseline visit), subjects must have demonstrated an untreated intraocular pressure between 24 and $35 \mathrm{mmHg}$ in at least one eye. They then underwent baseline diurnal curve intraocular pressure measurements at 0800, 1200 and $1600 \mathrm{~h}$. Subjects also completed an ocular and systemic symptom query. They were then randomly assigned to the masked study medication consisting of either one bottle of the latanoprost $0.005 \%$ / timolol maleate $0.5 \%$ fixed combination (dosed at 0800) and two bottles of placebo (vehicle) dosed at 2000, or brimonidine $0.2 \%$ dosed twice daily at 0800 and $2000 \mathrm{~h}$ and latanoprost $0.005 \%$ dosed at 2000. In this trial, the fixed combination latanoprost $0.005 \%$ and vehicle products were supplied by Pfizer in identical bottles and dosed per label. Subjects were asked to use the medications $5 \mathrm{~min}$ apart. Both the study personnel and subjects were masked to the medication.

Subjects returned after 2 weeks for a safety check (Visit 3 , Week 2), and then again after 4 weeks for the end of Period 1 intraocular pressure diurnal curve and symptom surveys (Visit 4, Week 6). Subjects were dosed with the Period 1 study medicine after the 0800 trough pressure measurement, and the pressure was again measured at 1200 and $1600 \mathrm{~h}$. Subjects were then switched to the Period 2 medication. They returned after two weeks for the Period 2 safety check (Visit 5, Week 8) and then again in 4 weeks for the end of Period 2 assessments, including the diurnal curve of the intraocular pressure, and symptom surveys performed as in Period 1 (Visit 6, Week 12). Subjects were then exited from the study. 


\section{Statistics}

The primary efficacy variable was the diurnal intraocular pressure difference between Visits 4 and 6 . This was analysed by a paired $t$-test for intragroup analysis. The diurnal curve was an average of the three daytime pressure measurements. An average eye analysis was used. A 0.05 alpha level was used to declare the significance. ${ }^{2}$ The standard deviation used to determine the power was $2.8 \mathrm{mmHg}{ }^{3-6}$ This study, with 30 subjects, provided at least an $80 \%$ power so that a $1.5 \mathrm{mmHg}$ difference could be excluded between groups. In all, 35 subjects were entered to assure that 30 were available for an intent-to-treat analysis. The secondary efficacy variable, intraocular pressure at each time point, as well as the diurnal intraocular pressure, was also analyzed by a paired $t$-test. ${ }^{2} \mathrm{~A}$ two-sided comparison was used to compare treatments and a one-sided comparison from baseline.

Safety parameters for intragroup analysis were evaluated with the Wilcoxon sign rank test including ocular as well as the systemic symptom queries. ${ }^{2}$ Visual acuity was analysed by the paired $t$-test. ${ }^{2}$ Adverse events were evaluated with a McNemar test. ${ }^{7}$ The statistical program that was used was JMP version 4.0.5 (SAS Institute Inc., Cary, NC, USA).

\section{Results}

\section{Subjects}

We enrolled 36 subjects in the study. One subject, whose efficacy data could not be used for the study, discontinued early due to a central retinal vein occlusion while being treated with the brimonidine $0.2 \%$ and latanoprost $0.005 \%$. This patient, a 63-year-old Caucasian female, had a history of systemic hypertension and hypercholesterolaemia with a previous central retinal vein occlusion in 1990 in the left eye. In the current study, upon treatment with the study preparation, the vein occlusion occurred in the right eye at a pressure of $20 \mathrm{mmHg}$ on the last study visit. No precipitating cause or event could be determined, but the investigator
(EDS) felt that a relationship to the latanoprost was possible.

Three additional subjects were removed from a study treatment early, but trough data were available for both periods. One had a lack of efficacy (the latanoprost $0.005 \% /$ timolol maleate $0.5 \%$ fixed combination), one experienced severe conjunctival hyperaemia and burning (both brimonidine $0.2 \%$ and latanoprost $0.005 \%$ and the latanoprost $0.005 \% /$ timolol maleate $0.5 \%$ fixed combination treatments), and one had redness, irritation, dryness, papillary reaction, and conjunctival hyperaemia while taking the brimonidine $0.2 \%$ and latanoprost $0.005 \%$ treatment. The subject characteristics for this trial are listed in Table 1.

\section{Intraocular pressure}

The intraocular measurements for the diurnal curve in the study are shown in Table 2 and in Figure 1. At each

Table 1 Subject characteristics (number of patients)

\begin{tabular}{ll}
\hline Age (years) & $64.5 \pm 10.7$ \\
Race & 15 \\
$\quad$ Caucasian & 20 \\
African American & \\
Iris color & 8 \\
Blue & 24 \\
Brown & 2 \\
Hazel & 1 \\
Grey & \\
Gender & \\
Male & 12 \\
Female & 23 \\
& \\
Diagnosis & \\
Ocular hypertension & 10 \\
Primary open-angle glaucoma & 24 \\
Pseudoexfoliation & 1 \\
& \\
Visual acuity & \\
Baseline & \\
Latanoprost/timolol maleate fixed combination & $0.06 \pm 0.14$ \\
Brimonidine and latanoprost & $0.05 \pm 0.15$ \\
P-value & 0.76 \\
\hline
\end{tabular}

Table 2 Mean intraocular pressure ( $\mathrm{mmHg} \pm$ standard deviation)

\begin{tabular}{|c|c|c|c|c|c|}
\hline Time point & $\mathrm{N}$ & Baseline & Latanoprost/timolol maleate fixed combination & Brimonidine + latanoprost & P-value \\
\hline Trough $(0800)$ & 35 & $26.9 \pm 3.2$ & $18.6 \pm 4.6$ & $18.0 \pm 4.0$ & 0.54 \\
\hline 1200 & 32 & $25.9 \pm 4.0$ & $18.0 \pm 2.8$ & $16.2 \pm 3.2$ & 0.02 \\
\hline 1600 & 32 & $25.0 \pm 4.1$ & $16.8 \pm 2.3$ & $17.2 \pm 2.6$ & 0.56 \\
\hline Diurnal & 32 & $26.0 \pm 3.4$ & $17.8 \pm 2.5$ & $17.2 \pm 2.8$ & 0.31 \\
\hline Baseline trough & 35 & & $8.3 \pm 4.0$ & $8.9 \pm 3.5$ & 0.48 \\
\hline Baseline 1200 & 32 & & $8.0 \pm 3.7$ & $9.8 \pm 4.0$ & 0.07 \\
\hline Baseline 1600 & 32 & & $8.2 \pm 3.7$ & $7.8 \pm 3.5$ & 0.70 \\
\hline Diurnal & 32 & & $8.2 \pm 2.9$ & $8.9 \pm 3.0$ & 0.36 \\
\hline
\end{tabular}




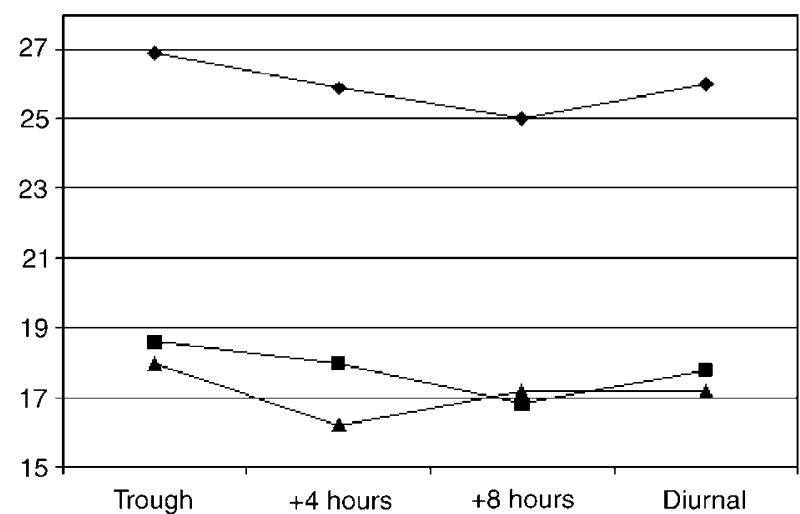

Figure 1 Diurnal intraocular pressures at baseline (diamonds) vs treatment with the latanoprost $0.005 \%$ /timolol maleate $0.5 \%$ fixed combination (squares) given each morning vs treatment with brimonidine $0.2 \%$ twice daily and latanoprost $0.005 \%$ (triangles) given each evening.

time point, both the latanoprost $0.005 \%$ / timolol maleate $0.5 \%$ fixed combination and the concomitant brimonidine $0.2 \%$ and latanoprost $0.005 \%$ provided an equal statistical reduction in intraocular pressure from baseline and for the diurnal curve. When treatment groups were compared to each other, there was no statistical difference between the groups for the diurnal curve $(P>0.05)$. However, a greater reduction was observed at $1200 \mathrm{~h}$ for brimonidine $0.2 \%$ and latanoprost $0.005 \%$ therapy, but not at the other time points (0800 and $1600 \mathrm{~h})$.

\section{Adverse events}

Ocular adverse events are shown in Table 3. There was no statistical difference in any individual adverse event between treatment groups $(P>0.05)$. In all, 35 total ocular adverse events were observed in the latanoprost $0.005 \%$ / timolol maleate $0.5 \%$ fixed-combination group and 41 in the brimonidine $0.2 \%$ and latanoprost $0.005 \%$ group. Systemic adverse events are shown in Table 4 . No difference was observed between groups for any individual event $(P>0.05)$. There were 14 total systemic adverse events in the latanoprost $0.005 \%$ / timolol maleate $0.5 \%$ fixed-combination group and nine in the brimonidine $0.2 \%$ and latanoprost $0.005 \%$ group.

The solicited symptom surveys showed no differences between treatments, nor from baseline, for all solicited questions including ocular effects of dry eye, blurred vision, tearing, burning on instillation, crusting of the eyelid, itching, sandy/gritty feeling, deep pain, or if the subjects and/or their acquaintance noticed ocular hyperaemia; or systemic effects including: fatigue, dizziness, despondency, depression, and dry mouth $(P>0.05)$
Table 3 Ocular adverse events (number of subjects, two or more events)

\begin{tabular}{lccc}
\hline Side effect & $\begin{array}{c}\text { Latanoprost/ } \\
\text { timolol } \\
\text { maleate fixed } \\
\text { combination }\end{array}$ & $\begin{array}{c}\text { Brimonidine+ } \\
\text { latanoprost }\end{array}$ & P-value \\
\hline $\begin{array}{l}\text { Conjunctival } \\
\text { hyperaemia }\end{array}$ & 13 & 18 & 0.23 \\
$\begin{array}{l}\text { Stinging/burning } \\
\text { Blurred vision }\end{array}$ & 4 & 4 & N/A \\
$\begin{array}{l}\text { Itching upon } \\
\text { instillation }\end{array}$ & 3 & 3 & N/A \\
$\begin{array}{l}\text { Foreign body } \\
\text { sensation }\end{array}$ & 2 & 2 & 0.64 \\
$\begin{array}{l}\text { Superficial punctate } \\
\text { keratitis }\end{array}$ & 2 & 3 & 0.64 \\
$\begin{array}{l}\text { Ocular pain } \\
\begin{array}{l}\text { Ocular dryness } \\
\text { Conjunctival papillary } \\
\text { response }\end{array}\end{array}$ & 2 & 3 & 0.64 \\
$\begin{array}{l}\text { Trace cells in anterior } \\
\text { chamber (uveitis) }\end{array}$ & 1 & 1 & 0.30 \\
\begin{tabular}{l} 
Mucus \\
\hline
\end{tabular} & 0 & 2 & N/A \\
\hline
\end{tabular}

Table 4 Systemic Adverse Events (number of events, two or more events)

\begin{tabular}{lccc}
\hline Side effect & $\begin{array}{c}\text { Latanoprost/ } \\
\text { timolol } \\
\text { maleate fixed } \\
\text { combination }\end{array}$ & $\begin{array}{c}\text { Brimonidine+ } \\
\text { latanoprost }\end{array}$ & P-value \\
\hline Dizziness & 3 & 1 & 0.30 \\
$\begin{array}{l}\text { Dental problem } \\
\quad \text { nonspecific) }\end{array}$ & 2 & 1 & 0.56 \\
$\begin{array}{l}\text { Ear infection } \\
\text { Benign dermal cyst }\end{array}$ & 1 & 1 & N/A \\
$\begin{array}{l}\text { Sinus infection } \\
\text { Worsened } \\
\text { hypertension }\end{array}$ & 0 & 1 & N/A \\
\hline
\end{tabular}

\section{Discussion}

The latanoprost $0.005 \%$ / timolol maleate $0.5 \%$ fixed combination has been under development by Pfizer for the past several years. Morning dosing of the latanoprost $0.005 \%$ / timolol maleate $0.5 \%$ fixed combination has been evaluated in several multi-centre studies in Europe and the United States. In Germany, Pfeiffer and associates ${ }^{8}$ have shown that the latanoprost $0.005 \%$ /timolol maleate $0.5 \%$ fixed combination reduced the intraocular pressure further compared to timolol maleate $0.05 \%$ alone, by $1.9 \mathrm{mmHg}$, and from latanoprost $0.005 \%$ alone by $1.2 \mathrm{mmHg}$. In the United States, the latanoprost $0.005 \%$ / timolol maleate $0.5 \%$ fixed combination reduced the intraocular pressure compared to timolol maleate $0.5 \%$ alone by another $2.9 \mathrm{mmHg}$ and compared to latanoprost $0.005 \%$ alone by another $1.1 \mathrm{mmHg}{ }^{9}$ 
Compared to other adjunctive treatments, Stewart and associates have noted that the latanoprost $0.005 \%$ / timolol maleate $0.5 \%$ fixed combination was more effective at 6-12 $\mathrm{h}$ after dosing, and for the end of the daytime diurnal curve than brimonidine $0.2 \%$ and timolol maleate $0.5 \% .^{1}$ In addition, Feldman and coworkers have recently shown that the latanoprost $0.005 \% /$ timolol maleate $0.5 \%$ fixed combination demonstrated a $1 \mathrm{mmHg}$ more pressure reduction during the daytime diurnal curve than the dorzolamide 2\%/ timolol maleate $0.5 \%$ fixed combination (Feldman RM, ARVO Abstract \#295, 2002). Little information is available, however, regarding the latanoprost $0.005 \%$ / timolol maleate $0.5 \%$ fixed combination compared to the concomitant use of brimonidine $0.2 \%$ and latanoprost $0.005 \%$ as adjunctive therapy.

In this current trial, we evaluated the efficacy and safety of the latanoprost $0.005 \%$ /timolol maleate $0.5 \%$ fixed-combination product, dosed each morning, vs brimonidine $0.2 \%$ given twice daily and latanoprost $0.005 \%$ dosed each evening in primary open-angle glaucoma or ocular hypertensive subjects.

This study found that both the latanoprost $0.005 \%$ / timolol maleate $0.5 \%$ fixed-combination treatment as well as brimonidine $0.2 \%$ and latanoprost $0.005 \%$ concomitant therapy statistically reduced the intraocular pressure from untreated baseline at each measured time point $(0800,1200$ and $1600 \mathrm{~h})$ and for the daytime diurnal curve (average of the three time points). When compared directly at the 0800 and 1600 time points and for the daytime diurnal curve, both treatments were statistically comparable. However, there was a greater efficacy for the brimonidine $0.2 \%$ and latanoprost $0.005 \%$ therapy $4 \mathrm{~h}$ after dosing (1200). This is consistent with the peak activity of brimonidine $0.2 \%$ noted in previous trials. ${ }^{1,10}$ In contrast, the extent of reduction for each therapy from baseline was not statistically different at each time point and for the diurnal curve.

The results of the study differ from a previous trial, performed by Stewart and associates ${ }^{1}$, that compared the latanoprost $0.005 \% /$ timolol maleate $0.5 \%$ fixed combination dosed each evening to brimonidine $0.2 \%$ and timolol maleate $0.5 \%$ each given twice daily. In that study, a statistical greater reduction in pressure with the fixed combination was shown with every 2-h diurnal curve testing $v$ s brimonidine $0.2 \%$ and timolol maleate $0.5 \%$ at $6-12 \mathrm{~h}$ after dosing. The addition of brimonidine $0.2 \%$ compared to timolol maleate $0.5 \%$ as monotherapy allowed for only a $1 \mathrm{mmHg}$ further reduction in pressure at the afternoon time points. These data are consistent with previous data by Stewart and coworkers ${ }^{11}$ that showed that brimonidine $0.2 \%$ monotherapy did not reduce the pressure at 10 and $12 \mathrm{~h}$ after morning dosing.
The differences between the current and previous trial evaluating the latanoprost $0.005 \%$ /timolol maleate $0.5 \%$ fixed combination are unclear, but could be based on several reasons. First, in the comparative group, latanoprost $0.005 \%$ was used instead of timolol maleate $0.5 \%$. Most clinical studies have shown that, as monotherapy, latanoprost $0.005 \%$ is more effective in reducing the intraocular pressure than timolol maleate $0.5 \% .^{12-14}$ This change in study design may have equalized the efficacy between treatment groups. Second, it is possible that the similar effect between groups was observed because the latanoprost $0.005 \%$ /timolol maleate $0.5 \%$ fixed combination was dosed in the morning according to label. Stewart and associates ${ }^{12}$ and Alm and coworkers ${ }^{15}$ have previously shown that nighttime dosing of latanoprost $0.005 \%$ provides lower daytime pressures. More recently, Konstas and associates demonstrated that latanoprost $0.005 \%$ and timolol maleate $0.5 \%$ once daily dosed concomitantly at night provided a lower daytime pressure and dosing in the morning allowed for lower evening pressures. ${ }^{16}$ Possibly, if the latanoprost $0.005 \%$ /timolol maleate $0.5 \%$ fixed combination had been dosed at night in the current study, a greater daytime efficacy could have been observed.

Regarding safety, there was no statistical difference in the overall number of adverse events, or in individual adverse events, between treatment groups. One subject, whose efficacy data could not be used for the study, discontinued early due to a central retinal vein occlusion while being treated with the brimonidine $0.2 \%$ and latanoprost $0.005 \%$. Three additional subjects were removed from a study treatment early, but trough data were available for both periods. One had a lack of efficacy (the latanoprost $0.005 \%$ / timolol maleate $0.5 \%$ fixed combination), one experienced severe conjunctival hyperaemia and burning (both brimonidine $0.2 \%$ and latanoprost $0.005 \%$ and the latanoprost $0.005 \% /$ timolol maleate $0.5 \%$ fixed-combination treatments), and one had redness, irritation, dryness, papillary reaction, and conjunctival hyperaemia while taking the brimonidine $0.2 \%$ and latanoprost $0.005 \%$. The symptom surveys showed no difference between active treatments or from baseline for any ocular or systemic question.

This study suggests that both the latanoprost $0.005 \%$ / timolol maleate $0.5 \%$ fixed combination dosed each morning and concomitant therapy of brimonidine $0.2 \%$ twice daily and latanoprost $0.005 \%$ dosed each evening provide statistically similar diurnal intraocular pressure reduction from an untreated baseline.

This study did not evaluate the study treatments compared to a latanoprost $0.005 \%$ run-in. Previous data have shown an additive effect of the latanoprost $0.005 \%$ / timolol maleate $0.5 \%$ fixed combination compared to 
latanoprost $0.005 \%$ morning or evening dosing only. 8,9 However, no previous data have examined the additive effect of brimonidine $0.2 \%$ twice daily dosing to latanoprost $0.005 \%$. Further research will hopefully further the comparative efficacy between these treatments.

\section{References}

1 Stewart WC, Stewart JA, Day D, Sharpe ED. Efficacy and safety of latanoprost/timolol maleate fixed combination versus timolol maleate and brimonidine given twice daily. Acta Ophthalmol Scand 2003; 81: 242-246.

2 Book SA Essentials of Statistics. McGraw Hill Book Company: New York, 1978, pp 117-122, 205-215.

3 Mundorf TK, Cate EA, Sine CS, Otero DW, Stewart JA, Stewart WC. The safety and efficacy of switching timolol maleate $0.5 \%$ solution to timolol hemihydrate $0.5 \%$ solution given twice daily. J Ocular Pharm Therap 1998; 14: 129-135.

4 Duff GR. A double-masked crossover study comparing the effects of carteolol $1 \%$ and $2 \%$ on intraocular pressure. Acta Ophthalmol 1987; 65: 618-621.

5 Stewart WC, Sharpe ED, Harbin Jr TS, Pastor SA, Day DG, Holmes KT et al. Brimonidine $0.2 \%$ versus dorzolamide $2 \%$ each given three times daily to reduce the intraocular pressure. Am J Ophthalmol 2000; 129: 723-727.

6 Stewart WC, Day DG, Sharpe ED, Dubiner HB, Holmes KT, Stewart JA. Efficacy and safety of timolol solution once daily vs timolol gel added to latanoprost. Am J Ophthalmol 1999; 128: 692-696.

7 Siegel S Nonparametric Statistics for the Behavioral Science. Series in Psychology. McGraw Hill Book Company,. New York, 1956, pp 63-67.

8 Pfeiffer N, and the German Latanoprost Fixed Combination Study Group. A comparison of the fixed combination of latanoprost and timolol with IST individual components in patients with glaucoma or ocular hypertension. Invest Ophthalmol Vis Sci 2000; 41 (suppl): S754.

9 Higginbotham EJ, Feldman R, Stiles M, Dubiner H, Fixed Combination Investigative Group. Latanoprost and timolol combination therapy versus monotherapy. Arch Ophthalmol 2002; 120: 915-922.

10 Stewart WC, Day DG, Stewart JA, Schuhr J, Latham KE. The efficacy and safety of latanoprost $0.005 \%$ once daily versus brimonidine $0.2 \%$ twice daily in open-angle glaucoma or ocular hypertension. Am J Ophthalmol 2001; 131: 631-635.

11 Stewart WC, Holmes KT, Johnson MA. Washout periods for brimonidine $0.2 \%$ and latanoprost $0.005 \%$. Am J Ophthalmol 2001; 131: 798-799.

12 Alm A, Stjernschantz J and the Scandinavian Latanoprost Study Group. Effects on intraocular pressure and side effects of $0.005 \%$ latanoprost applied once daily, evening or morning: a comparison with timolol. Ophthalmology 1995; 102: $1743-1752$.

13 Camras CB and the United States Latanoprost Study Group. Comparison of latanoprost and timolol in patients with ocular hypertension and glaucoma: a six-month, masked, multicenter trial in the United States. Ophthalmology 1996; 103: 138-147.

14 Watson P, Stjernschantz J, and the Latanoprost Study Group. A six-month, randomized, double-masked study comparing latanoprost with timolol in open-angle glaucoma and ocular hypertension. Ophthalmology 1996; 103: 126-137.

15 Konstas AGP, Maltezos AC, Gandi S, Hudgins AC, Stewart WC. Comparison of the 24 hour intraocular pressure reduction with two dosing regimes of latanoprost and timolol in patients with open-angle glaucoma. Am J Ophthalmol 1999; 128: 15-20.

16 Konstas AGP, Nakos E, Tersis I, Lallos NA, Leech JN, Stewart WC. A comparison of once daily morning versus evening dosing of concomitant latanoprost/timolol. Am J Ophthalmol 2002; 133: 753-757. 